\title{
ANALISIS KOMPARATIF KINERJA KEUANGAN BPRS LINKAGE PROGRAM DAN NON LINKAGE PROGRAM PERIODE 2014-2015 13
}

\author{
Allen Anandika Rizky Pratama \\ Mahasiswa Program Studi Ekonomi Islam-Fakultas Ekonomi dan Bisnis-Universitas Airlangga \\ Email: allen.anandika-12@feb.unair.ac.id
}

Achsania Hendratmi

Departemen Ekonomi Syariah-Fakultas Ekonomi dan Bisnis-Universitas Airlangga

Email: achsania.hendratmi@feb.unair.ac.id

\begin{abstract}
:
This research aims to discover whether there are any differences in financial performance between BPRS which take part in the linkage program and the one which do the contrary, in period of 30 March 2014 - 30 December 2015. The method used in this research is quantitative where the research is done by doing a descriptive statistical analysis and inferential statistic. The comparison of the financial performances are based on financial ratio assessment consisting of CAR, NPF, ROA, BOPO and FDR. Research shows that there are indeed found differences in financial performance between BPRS which take part in the linkage program and the one which do the contrary. Differences in financial performance viewed from financial ratio of FDR, NPF and CAR. However, earning ratio (rentabilitas)ROA and BOPO not possessed any differences between BPRS which take part in the linkage program and BPRS which does not.
\end{abstract}

Keywords: financial performance comparison, sharia bank financing, linkage program.

\section{PENDAHULUAN}

\section{Latar Belakang}

Setelah berdirinya Bank Umum Syariah (BUS), muncul Bank Perkreditan Rakyat (BPR). Istilah Bank Perkreditan Rakyat (BPR) diperkenalkan pertama kali oleh Bank Rakyat Indonesia (BRI) pada akhir tahun 1977, ketika BRI mulai menjalankan tugasnya sebagai Bank pembina lumbung desa, bank pasar, bank desa, bank pegawai dan bank-bank sejenis lainnya. Pada masa pembinaan yang dilakukan oleh BRI, seluruh bank tersebut diberi nama Bank Perkreditan Rakyat (BPR) (Sumitro, 2002:111).

Berdirinya Bank Pembiayaan Rakyat Syariah (BPRS), selain didasari oleh tuntutan bermuamalah secara Islam yang merupakan keinginan kuat dari sebagian besar umat Islam di Indonesia, juga sebagai langkah aktif dalam rangka restrukturisasi perekonomian Indonesia yang dituangkan dalam berbagai paket kebijaksanaan keuangan, moneter, perbankan secara umum. Secara khusus adalah mengisi peluang terhadap kebijaksanaan yang membebaskan bank dalam penetapan tingkat suku bunga (rate interest), yang kemudian dikenal dengan bank tanpa bunga (Sumitro, 2002:112).

Menurut UU No. 21 tahun 2008 tentang Perbankan Syariah, penyaluran dana oleh Bank Pembiayaan Rakyat Syariah (BPRS) berupa pembiayaan dengan akad transaksi bagi hasil, sewa menyewa, jual beli, pinjam meminjam, 
dan sewa menyewa jasa (multijasa). Penerapan prinsip syariah dalam Bank Pembiayaan Rakyat Syariah (BPRS) tidak hanya sekedar dalam hal pembiayaan kepada usaha mikro, kecil, menengah, terkhusus pada daerah-daerah kecil seperti desa yang memang pada daerah yang dianggap kecil tersebut masih banyak masyarakat yang membutuhkan pembiayaan.

Berdirinya Bank Pembiayaan Rakyat Syariah (BPRS) di daerah-daerah kecil dikarenakan Bank Pembiayaan Rakyat Syariah (BPRS) mempunyai tujuan operasional untuk meningkatkan kesejahteraan masyarakat yang ada di daerah-daerah kecil dengan mempunyai harapan terciptanya kesejahteraan ekonomi yang merata.

Bank Pembiayaan Rakyat Syariah (BPRS) mempunyai fungsi pelayanan dengan jangkauan yang lebih luas kepada masyarakat. Dalam upaya pencapaian tujuan tersebut, Bank Indonesia membuat program bernama linkage program, program ini adalah kerjasama yang dilaksanakan bank umum kepada Lembaga Keuangan Mikro dalam bentuk pembiayaan sebagai upaya untuk meningkatkan kegiatan Usaha Mikro, Kecil dan Menengah (UMKM) (Outlook Perbankan Syariah Tahun 2012).

Kegiatan usaha yang dilakukan BPR dan BPRS salah satunya adalah memberikan kredit atau pembiayaan untuk Usaha Mikro, Kecil dan Menengah (UMKM), maka dari itu Bank Indonesia membuat suatu program untuk mempermudah penyaluran kredit atau pembiayaan tersebut, sehingga dibuatlah Peraturan Bank Indonesia NOMOR: 9/6/PBI/2007 Pasal 24 Ayat 2 yang berisi tujuan Linkage Program ke Bank Perkreditan Rakyat (BPR), Bank Pembiayaan Rakyat Syariah (BPRS) dan Bank Umum. Linkage Program menurut Peraturan Bank Indonesia NOMOR: 9/6/PBI/2007 (pada halaman 11) yaitu kerjasama Bank Umum dengan BPR dan BPRS dalam rangka pembiayaan kepada UMKM sehingga mempermudah bank umum dalam hal meminjamkan dananya ke BPR dan BPRS untuk disalurkan lagi ke UMKM dalam hal pemberian kredit dan pembiayaan.

Linkage program adalah program pembiayaan yang bersifat kemitraan, bank umum mengeluarkan pembiayaan ke sektor UMKM secara tidak langsung namun menyalurkannya melalui Bank Pembiayaan Rakyat Syariah (BPRS) sebagai agen penyaluran. Linkage program dibagi menjadi 3 jenis, yaitu executing, channeling, dan joint financing.

Linkage program adalah program pembiayaan yang bersifat kemitraan. Bank umum mengeluarkan pembiayaan ke sektor riil secara tidak langsung namun menyalurkannya melalui koperasi atau Lembaga Keuangan Mikro (LKM) sejenis. Adanya linkage program ini, diharapkan dapat mendorong kinerja BPR dan BPRS dalam menyalurkan kredit atau pembiayaan kepada masyarakat. Dari linkage program ini dianggap penting 
untuk menunjang kemajuan dan peningkatan keadaan ekonomi di sektor riil pada masyarakat. Program ini berlandaskan asas tolong-menolong antar sesama, sebagaimana telah dituliskan di Al-Qur'an pada Surat Al-Maidah ayat 2, dibawah ini:

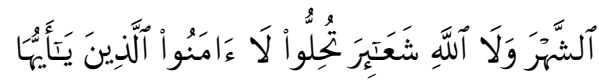

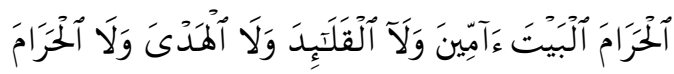

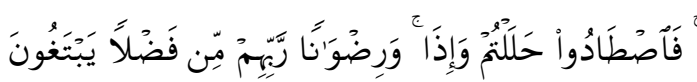

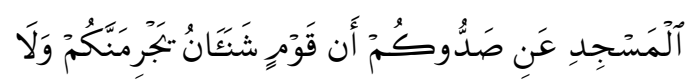

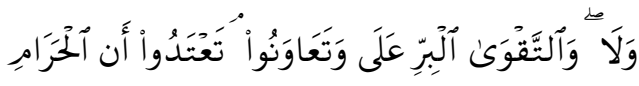

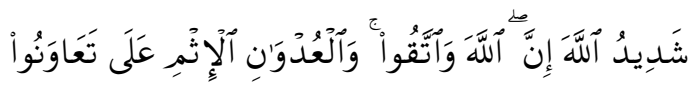

$$
\begin{aligned}
& \text { آلَّعِقَابِ }
\end{aligned}
$$

Yang artinya "Hai orang-orang yang beriman, janganlah kamu melanggar syi'ar-syi'ar Allah, dan jangan melanggar kehormatan bulan-bulan haram, jangan (mengganggu) binatang-binatang hadya, dan binatang-binatang qalaa-id, dan jangan (pula) mengganggu orang-orang yang mengunjungi Baitullah sedang mereka mencari kurnia dan keredhaan dari Tuhannya dan apabila kamu telah menyelesaikan ibadah haji, Maka bolehlah berburu. dan janganlah sekalikali kebencian(mu) kepada sesuatu kaum karena mereka menghalang-halangi kamu dari Masjidilharam, mendorongmu berbuat aniaya (kepada mereka). dan tolong-menolonglah kamu dalam (mengerjakan) kebajikan dan takwa, dan jangan tolong-menolong dalam berbuat dosa dan pelanggaran. dan bertakwalah kamu kepada Allah, Sesungguhnya Allah Amat berat siksa-Nya" (Q.S. Al Maidah:2) Konsep kemitraan harus memiliki tujuan dasar yakni saling menguntungkan, namun bukan berarti para pihak yang bermitra harus memiliki partisipasi dan kemampuan yang sama akan tetapi yang lebih utama adalah posisi tawar yang seimbang berdasarkan peran masingmasing pihak yang bermitra (Septian, 2013:8).

Bank-bank syariah memperkuat linkage program dengan bank perkreditan rakyat syariah. Ketua Asbisindo Jatim Ersyam Fansuri mengatakan bahwa linkage program antar BPRS dan bank syariah terus diperkuat agar penetrasi bank-bank berbasis syariah tersebut semakin masif dan saling mendukung satu sama lain. Sekarang baru ada 4 BPRS yang mengikuti linkage program yaitu BPRS Artha Pamenang, BPRS Rahma Syariah, BPRS Madina dan BPRS Barokah.

Didasarkan atas penjelasan mengenai fungsi Bank Pembiayaan Rakyat Syariah (BPRS) dan keberadaan linkage program ini mendorong peneliti untuk mendalami lebih lanjut mengenai dampak lingkage program terhadap kinerja keuangan Bank Pembiayaan Rakyat Syariah (BPRS). Hubungan linkage program dan kinerja keuangan dapat dikaitkan dengan hasil laporan keuanganan tahunan dari pihak bank itu sendiri. Analisis pada laporan keuangan adalah salah satu cara menilai keadaan suatu perusahaan mulai dari penilaian kelangsungan usaha, stabilitas perusahaan, dan profitabilitas dari suatu usaha.

Pada pengamatan ini, penilaian kinerja keuangan menjadi bagian yang sangat penting. Pada laporan keuangan Bank Pembiayaan Rakyat Syariah (BPRS) akan tersaji laporan neraca, laporan laba 
Pratama, et al/Jurnal Ekonomi Syariah Teori dan Terapan Vol. 4 No. 6 Juni 2017: 493-504; ANALISIS KOMPARATIF KINERJA KEUANGAN BPRS LINKAGE PROGRAM DAN NON LINKAGE PROGRAM PERIODE 2014-2015

rugi, laporan komitmen dan kontijensi, laporan kualitas aktiva produktif dan informasi lainnya, sumber dan penggunaan ZIS, sumber dan penggunaan Qardhul Hasan, distribusi bagi hasil, dan perubahan dana investasi terikat.

Penelitibermaksud membandingan kinerja keuangan Bank Pembiayaan Rakyat Syariah (BPRS) yang mengikuti dan yang tidak mengikuti linkage program. BPRS Tanmiya Artha Kediri dan BPRS Daya Artha Mentari menjadi subjek penelitian sebagai BPRS yang tidak mengikuti linkage program. Adapun alat analisis kinerja keuangan yaitu menggunakan rasio Capital Adequacy Ratio (CAR), faktor aset dengan rasio Non Performing Financing (NPF), faktor rentabilitas dengan rasio Return On Assets (ROA) dan Beban Operasional Pendapatan Operasional (BOPO) dan faktor likuiditas dengan rasio Financing to Deposit Ratio (FDR).

Analisis rasio keuangan merupakan metode analisis yang sering dipakai karena merupakan metode yang paling cepat untuk mengetahui kinerja keuangan suatu perusahaan.

Didasarkan penjelasan mengenai fungsi Bank Pembiayaan Rakyat Syariah (BPRS) dan keberadaan linkage program ini mendorong peneliti untuk lebih lanjut membahas mengenai dampak linkage program terhadap kinerja keuangan Bank Pembiayaan Rakyat Syariah (BPRS). Dari keterangan tersebut, peneliti mengambil judul "Analisis Komparatif Kinerja
Kevangan BPRS Linkage Program dan Non Linkage Program Periode 2014-2015"

\section{LANDASAN TEORI}

Tugas Bank Pembiayaan Rakyat Syariah (BPRS) adalah menghimpun dana dari masyarakat dan menyalurkan dana tersebut dalam bentuk pembiayaan kepada masyarakat yang dinilai membutuhkan suatu pembiayaan. Segala kegiatan penghimpunan dana maupun penyaluran dana didasarkan oleh suatu akad yang ada dari produk-produk yang dipilih oleh nasabah/masyarakat (Ismail, 2011:55).

Selain bertindak sebagai pihak yang melakukan penghimpunan dana dari masyarakat dan menyalurkannya kepada masyarakat yang membutuhkan dana, dalam UU No. 21 Tahun 2008 pasal 4 ayat 2 dan 3 juga menjelaskan bahwa bank syariah dalam hal ini adalah Bank Pembiayaan Rakyat Syariah (BPRS) dapat melaksanakan fungsi sosial dalam bentuk lembaga baitul maal, yaitu menerima dana yang berasal dari zakat, infaq, sedekah, hibah dan dana sosial lain dan menyalurkannya kepada organisasi pengelola zakat.

Melakukan pengukuran terhadap kinerja kevangan Bank Pembiayaan Rakyat Syariah (BPRS) sangat diperlukan, oleh sebabnya dari kegiatan tersebut pihak manajemen Bank Pembiayaan Rakyat Syariah (BPRS) dapat melakukan penilaian apakah perusahaan telah beroperasi secara efektif dan efisien baik dari segi penghimpunan dana atau dari segi penyaluran dana. Untuk mengukur 
kinerja keuangan Bank Pembiayaan Rakyat Syariah (BPRS), pihak manajemen Bank Pembiayaan Rakyat Syariah (BPRS) dapat melakukan analisis terhadap laporan kevangan Bank Pembiayaan Rakyat Syariah (BPRS).

Laporan keuangan adalah laporan yang menunjukkan kondisi keuangan perusahaan pada saat ini atau dalam suatu periode tertentu. Setiap perusahaan termasuk perusahaan perbankan wajib mempunyai laporan kevangan dikarenakan laporan keuangan merupakan salah satu bentuk transparanasi perusahaan tentang keadaan keuangan perusahaan terhadap pihak-pihak yang memiliki kepentingan dengan perusahaan yang bersangkutan.

Kinerja secara umum menggambarkan prestasi yang dicapai oleh bank dalam kegiatan operasionalnya sebagai lembaga penghimpun dan penyalur dana masyarakat (intermediasi). Kinerja menunjukkan sesatu yang berhubungan dengan kekuatan serta kelemahan suatu perusahaan. Kekuatan tersebut dipahami agar dapat dimanfaatkan dan kelemahan pun harus diketahui agar dapat dilakukan langkahlangkah perbaikan (Muhammad, 1997:151).

Penilaian kinerja bank umum syariah yaitu penilaian kuantitatif dan kualitatif terhadap faktor permodalan, aset, rentabilitas, sensitifitas terhadap risiko pasar serta penilaian kualitatif terhadap faktor manajemen. Penilaian kinerja kevangan bank syariah dapat dipergunakan oleh bank syariah untuk membuktikan kepada masyarakat bahwa bank tersebut dapat dipercaya karena dalam keadaan baik sehingga dapat beroperasi serta melayani masyarakat dengan baik (Kasmir, 2013:7).

Pada tahun 2004, Arsitektur Perbankan Indonesia (API) mengeluarkan generic model linkage program yang berisi mengenai aturan-aturan pelaksanaan linkage program antara bank umum dan Lembaga Keuangan Mikro, sehingga penerapan linkage program semakin jelas dan terarah.

Linkage program adalah program pembiayaan yang bersifat kemitraan, bank umum mengeluarkan pembiayaan ke sektor UMKM secara tidak langsung namun menyalurkannya melalui Bank Pembiayaan Rakyat Syariah (BPRS) sebagai agen penyaluran. Linkage program dibagi menjadi 3 jenis, yaitu executing, channeling, dan joint financing.

Linkage program adalah program pembiayaan yang bersifat kemitraan. Bank umum mengeluarkan pembiayaan ke sektor riil secara tidak langsung namun menyalurkannya melalui koperasi atau Lembaga Keuangan Mikro (LKM) sejenis. Adanya linkage program ini, diharapkan dapat mendorong kinerja BPR dan BPRS dalam menyalurkan kredit atau pembiayaan kepada masyarakat. Dari linkage program ini dianggap penting untuk menunjang kemajuan dan 
Pratama, et al/Jurnal Ekonomi Syariah Teori dan Terapan Vol. 4 No. 6 Juni 2017: 493-504; ANALISIS KOMPARATIF KINERJA KEUANGAN BPRS LINKAGE PROGRAM DAN NON LINKAGE PROGRAM PERIODE 2014-2015

peningkatan keadaan ekonomi di sektor riil pada masyarakat.

Membandingan kinerja keuangan Bank Pembiayaan Rakyat Syariah (BPRS) yang mengikuti dan yang tidak mengikuti linkage program. BPRS Tanmiya Artha Kediri dan BPRS Daya Artha Mentari menjadi subjek penelitian sebagai BPRS yang tidak mengikuti linkage program. Adapun alat analisis kinerja keuangan yaitu menggunakan rasio Capital Adequacy Ratio (CAR), faktor aset dengan rasio Non Performing Financing (NPF), faktor rentabilitas dengan rasio Return On Assets (ROA) dan Beban Operasional Pendapatan Operasional (BOPO) dan faktor likuiditas dengan rasio Financing to Deposit Ratio (FDR). Analisis rasio keuangan merupakan metode analisis yang sering dipakai karena merupakan metode yang paling cepat untuk mengetahui kinerja keuangan suatu perusahaan.

\section{METODE PENELITIAN}

\section{Pendekatan Penelitian}

Pendekatan yang dipergunakan dalam penelitian ini adalah pendekatan dengan metode kuantitatif. Hal ini dikarenakan, penelitian ini dilakukan untuk menguji hipotesis yang bertujuan untuk membuktikan asumsi yang ada sebelumnya, dengan menggunakan data terukur dan menghasilkan sebuah kesimpulan yang dapat dipertanggung jawabkan.

Teknik analisis yang digunakan adalah statistik deskriptif, yaitu teknik statistik yang dipergunakan untuk menganalisis data dengan
mendeskripsikan data yang telah
terkumpul sebelumnya.

\section{Identifikasi Variabel}

Variabel merupakan karakter atau sifat dari objek kajian yang relevan dengan permasalahan penelitian. Maka variabel dari penelitian ini adalah (1) Capital Adequacy Ratio (CAR), (2) Non Performing Financing, (3) Return On Asset (ROA), (4) Beban Operasional Pendapatan Operasional (BOPO) dan (5) Financing Deposit Ratio (FDR).

\section{Jenis dan Sumber Data}

Data yang dipergunakan dalam penelitian berupa laporan keuangan triwulanan 30 Maret 2014 hingga 30 Desember 2015. Variabel yang digunakan dalam penelitian berupa rasio yang telah dipubliskasikan dari pihak Bank Pembiayaan Rakyat Syariah (BPRS) dalam laporan keuangan tersebut.

\section{Sampel}

Sampel pada penelitian ini diambil secara purposive sampling karena ada pertimbangan tertentu. Sampel yang diambil sebanyak 4, 2 BPRS yang mengikuti linkage program dan 2 BPRS yang tidak mengikuti linkage program. BPRS Artha Pamenang dan BPRS Rahma Syariah (BPRS yang ikut linkage program) dan BPRS Tanmiya Artha dan BPRS Daya Artha Mentari (BPRS yang tidak ikut linkage program).

\section{Prosedur Pengumpulan Data}

Prosedur pengumpulan data yang dilakukan peneliti adalah sebagai berikut: 
1. Metode pengumpulan data pada penelitian ini adalah data primer dan data sekunder. Pada data primer, data diperoleh dari hasil wawancara dengan pihak BPRS untuk konfirmasi kepesertaan BPRS pada linkage program. Data sekunder diperoleh dari data yang berbentuk laporan keuangan yang dipublisikan di website OJK www.ojk.go.id

2. Studi kepustakaan, dilakukan dengan mengumpulkan dan mempelajari berbagai jurnal, buku pustaka, artikel, dan bahan-bahan lain yang digunakan untuk memahami permasalahan dan mendapat alternatif pemecahan masalah yang ada

3. Pengumpulan data penelitian ini dilakukan secara panel data (pooled data), karena dilakukan dengan melibatkan banyak sampel pada tiap periodenya (crosssection) dan melibatkan urutan waktu (timeseries).

\section{Teknik Analisis}

Teknik analisis data dalam penelitian kuantitatif menggunakan analisis statistik. Analisis data dalam penelitian ini menggunakan dua tahap, yaitu statistik deskriptif dan statistik inferensial. Statistik deskriptif adalah metode mengatur, merangkum, dan mempresentasikan data dengan cara yang informatif (Santoso, 2014:250).

Statistik deskriptif menyajikan nilai rata-rata (mean), nilai terendah (minimum) dan nilai tertinggi (maximum) dari rasio-rasio yang diujikan yaitu rasio Capital Adequacy Ratio (CAR), Non Performing Financing (NPF), Return On Asset (ROA), Beban Operasional Pendapatan Operasional (BOPO) dan Financing to Deposit Ratio (FDR) yang dimiliki bank yang menjadi sampel selama periode 2014-2015. Statistik deskriptif pada penelitian ini menggunakan program Ms.Excel 2007.

Statistik inferensial dalam penelitian ini menggunakan analisis parametrik dengan uji T test dan juga analisis non parametrik dengan Mann-Whitney test dengan menggunakan aplikasi SPSS 23.

\section{HASIL DAN PEMBAHASAN}

Setelah dilakukan analisis deskriptif pada rasio yang menjadi variabel dalam penelitian dilanjutkan dengan uji normalitas yang menjadi persyaratan sebelum melakukan uji beda. Data uji normalitas pada BPRS yang mengikuti linkage program dan BPRS yang tidak mengikuti linkage program dapat dilihat Tabel 1.

Tabel 1.

Uji Normalitas

\begin{tabular}{|c|c|c|c|c|c|}
\hline Var & $\begin{array}{c}\mathrm{Ke} \\
\dagger\end{array}$ & D & Stat & Sig & $\begin{array}{c}\text { Keteranga } \\
n\end{array}$ \\
\hline \multirow[t]{2}{*}{ CAR } & $L P$ & 8 & $\begin{array}{c}0,39 \\
5\end{array}$ & $\begin{array}{c}0,00 \\
1\end{array}$ & $\begin{array}{c}\text { Tidak } \\
\text { Terdistribusi } \\
\text { Normal }\end{array}$ \\
\hline & TLP & 8 & $\begin{array}{c}0,28 \\
1\end{array}$ & $\begin{array}{c}0,06 \\
3\end{array}$ & $\begin{array}{c}\text { Terdistribusi } \\
\text { Normal }\end{array}$ \\
\hline NPF & $L P$ & 8 & $\begin{array}{c}0,23 \\
8\end{array}$ & $\begin{array}{c}0,20 \\
0\end{array}$ & $\begin{array}{c}\text { Terdistribusi } \\
\text { Normal }\end{array}$ \\
\hline
\end{tabular}




\begin{tabular}{|c|c|c|c|c|c|}
\hline & TLP & 8 & $\begin{array}{c}0,14 \\
2\end{array}$ & $\begin{array}{c}0,20 \\
0\end{array}$ & $\begin{array}{c}\text { Terdistribusi } \\
\text { Normal }\end{array}$ \\
\hline \multirow{2}{*}{ ROA } & $L P$ & 8 & $\begin{array}{c}0,18 \\
5\end{array}$ & $\begin{array}{c}0,20 \\
0\end{array}$ & $\begin{array}{c}\text { Terdistribusi } \\
\text { Normal }\end{array}$ \\
\hline & TLP & 8 & $\begin{array}{c}0,20 \\
3\end{array}$ & $\begin{array}{c}0,20 \\
0\end{array}$ & $\begin{array}{c}\text { Terdistribusi } \\
\text { Normal }\end{array}$ \\
\hline \multirow{2}{*}{$\begin{array}{c}\text { BOP } \\
\text { O }\end{array}$} & $L P$ & 8 & $\begin{array}{c}0,16 \\
9\end{array}$ & $\begin{array}{c}0,20 \\
0\end{array}$ & $\begin{array}{c}\text { Terdistribusi } \\
\text { Normal }\end{array}$ \\
\hline & TLP & 8 & $\begin{array}{c}0,15 \\
0\end{array}$ & $\begin{array}{c}0,20 \\
0\end{array}$ & $\begin{array}{c}\text { Terdistribusi } \\
\text { Normal }\end{array}$ \\
\hline \multirow{2}{*}{ FDR } & $L P$ & 8 & $\begin{array}{c}0,20 \\
0\end{array}$ & $\begin{array}{c}0,20 \\
0\end{array}$ & $\begin{array}{c}\text { Terdistribusi } \\
\text { Normal }\end{array}$ \\
\hline & TLP & 8 & $\begin{array}{c}0,14 \\
2\end{array}$ & $\begin{array}{c}0,00 \\
0\end{array}$ & $\begin{array}{c}\text { Terdistribusi } \\
\text { Normal }\end{array}$ \\
\hline
\end{tabular}

Sumber: hasil uji SPSS (data telah diolah).

Dari hasil uji normalitas tersebut, maka dapat disimpulkan bahwa untuk variabel CAR dapat dilakukan uji beda menggunakan uji Mann-Whitney dikarenakan data variabel tersebut tidak normal, sedangkan untuk variabel NPF, ROA, BOPO dan FDR menggunakan independent sample $t$ test dikarenakan data variabel tersebut terdistribusi normal.

Uji Beda

Uji Beda CAR

Tabel 2.

Uji Beda CAR Mann-Whitney

\begin{tabular}{|c|c|c|c|c|}
\hline Var & $\begin{array}{c}\text { Kateg } \\
\text { ori }\end{array}$ & $\begin{array}{l}\text { Mean } \\
\text { Rank }\end{array}$ & Sig & Ket. \\
\hline \multirow[b]{2}{*}{ CAR } & $L P$ & 11,00 & \multirow[b]{2}{*}{$\begin{array}{c}0,03 \\
8\end{array}$} & \multirow{2}{*}{$\begin{array}{c}\mathrm{H}_{0} \\
\text { ditola } \\
\mathrm{k}\end{array}$} \\
\hline & TLP & 6,00 & & \\
\hline
\end{tabular}

Sumber: hasil uji SPSS (data telah diolah).
Berdasarkan tabel diatas hasil uji beda Mann-Whitney yang dilakukan pada variabel CAR untuk BPRS yang mengikuti linkage program dan BPRS yang tidak mengikuti linkage program, diketahui bahwa nilai signifikansi dari variabel ini adalah sebesar 0,038 yang lebih kecil dari 0,05 sehingga menunjukkan bahwa terdapat perbedaan kinerja keuangan antara BPRS yang mengikuti linkage program dan BPRS yang tidak mengikuti linkage program pada sisi CAR.

Uji Beda NPF

Tabel 3.

Uji Beda NPF Independent t test

\begin{tabular}{|c|c|c|c|c|c|}
\hline \multirow{2}{*}{$\begin{array}{c}\mathbf{V a} \\
\mathbf{r}\end{array}$} & & \multicolumn{2}{|c|}{$\begin{array}{c}\text { Levene's } \\
\text { Test }\end{array}$} & \multirow{2}{*}{ Sig. } & \multirow{2}{*}{$\begin{array}{c}\mathbf{K e} \\
\mathbf{t}\end{array}$} \\
\hline & & $\mathbf{F}$ & $\begin{array}{c}\text { Sig } \\
\text {. }\end{array}$ & & \\
\hline \multirow[b]{2}{*}{$\begin{array}{l}\text { NP } \\
\text { F }\end{array}$} & $\begin{array}{c}\text { Equal } \\
\text { variance } \\
\text { assumed }\end{array}$ & \multirow[b]{2}{*}{$\begin{array}{l}7,5 \\
22\end{array}$} & \multirow[b]{2}{*}{$\begin{array}{l}0,0 \\
16\end{array}$} & $\begin{array}{c}0,00 \\
1\end{array}$ & \\
\hline & $\begin{array}{c}\text { Equal } \\
\text { variance } \\
\text { not } \\
\text { assumed }\end{array}$ & & & $\begin{array}{c}0,00 \\
3\end{array}$ & $\begin{array}{c}\mathrm{H}_{0} \\
\text { dit } \\
\text { ola } \\
\mathrm{k}\end{array}$ \\
\hline
\end{tabular}

Sumber: hasil uji SPSS (data telah diolah).

Pada tabel diatas dapat diketahui bahwa variabel ini memiliki nilai signifikansi dari Levenne's test sebesar 0,016 yang lebih kecil dari 0,05 sehingga hasil uji yang digunakan adalah equal variance not assumed. Berdasarkan uji beda Independent sample t-test yang dilakukan pada variable NPF BPRS yang mengikuti linkage program dan BPRS yang tidak 
mengikuti linkage program, diketahui bahwa nilai signifikansi dari variabel ini pada bagian equal variance not assumed adalah sebesar 0,003 . Nilai signifikansi dari rasio ini lebih kecil dari 0,05 sehingga menujukkan bahwa terdapat perbedaan kinerja keuangan antara BPRS yang mengikuti linkage program dan BPRS yang tidak mengikuti linkage program.

\section{Uji Beda ROA}

Tabel 4.

Uji Beda Roa Independent sample t test

\begin{tabular}{|c|c|c|c|c|c|}
\hline \multirow[t]{2}{*}{ Var } & & \multicolumn{2}{|c|}{$\begin{array}{c}\text { Levene's } \\
\text { Test }\end{array}$} & \multirow[t]{2}{*}{ Sig. } & \multirow[t]{2}{*}{ Ket } \\
\hline & & $F$ & Sig. & & \\
\hline \multirow[b]{2}{*}{$\mathrm{ROA}$} & $\begin{array}{l}\text { Equal } \\
\text { varian } \\
\text { ces } \\
\text { assum } \\
\text { ed }\end{array}$ & \multirow[b]{2}{*}{$\begin{array}{l}10 \\
793\end{array}$} & \multirow[b]{2}{*}{0,005} & $\begin{array}{l}0,4 \\
56\end{array}$ & \\
\hline & $\begin{array}{c}\text { Equal } \\
\text { varian } \\
\text { ces } \\
\text { not } \\
\text { assum } \\
\text { ed }\end{array}$ & & & $\begin{array}{l}0,4 \\
66\end{array}$ & $\begin{array}{l}\mathrm{H}_{0} \\
\text { dit } \\
\text { eri } \\
\text { ma }\end{array}$ \\
\hline
\end{tabular}

Sumber: hasil uji SPSS (data telah diolah).

Pada tabel diatas dapat diketahui bahwa variabel ini memiliki nilai signifikansi dari Levene's test sebesar 0,005 yang lebih kecil dari 0,05 , sehingga hasil uji yang digunakan adalah equal variances not assumed. Berdasarkan uji beda Independent sample t-test yang dilakukan pada variabel ROA untuk BPRS yang mengikuti linkage program dan BPRS yang tidak mengikuti linkage program, diketahui bahwa nilai signifikansi dari variabel ini pada bagian equal variances not assumed adalah sebesar 0,466 . Nilai signifikansi dari rasio ini lebih besar dari 0,05 sehingga menunjukkan bahwa tidak terdapat perbedaan kinerja keuangan antara BPRS yang mengikuti linkage program dan BPRS yang tidak mengikuti linkage program pada sisi ROA.

\section{Uji Beda BOPO}

Tabel 5.

Uji Beda BOPO Independent sample † test

\begin{tabular}{|c|c|c|c|c|c|}
\hline \multirow[t]{2}{*}{ Var } & & \multicolumn{2}{|c|}{$\begin{array}{c}\text { Levene's } \\
\text { Test }\end{array}$} & \multirow[t]{2}{*}{ Sig. } & \multirow[t]{2}{*}{ Ket } \\
\hline & & $\mathbf{F}$ & Sig. & & \\
\hline \multirow{2}{*}{$\begin{array}{c}\text { BOP } \\
\mathrm{O}\end{array}$} & $\begin{array}{c}\text { Equal } \\
\text { varian } \\
\text { ce } \\
\text { assum } \\
\text { ed }\end{array}$ & \multirow{2}{*}{$\begin{array}{l}8,1 \\
22\end{array}$} & \multirow{2}{*}{$\begin{array}{c}0,01 \\
3\end{array}$} & $\begin{array}{c}0,04 \\
4\end{array}$ & \\
\hline & $\begin{array}{c}\text { Equal } \\
\text { varian } \\
\text { ce not } \\
\text { assum } \\
\text { ed }\end{array}$ & & & $\begin{array}{c}0,06 \\
0\end{array}$ & $\begin{array}{c}\mathrm{H}_{0} \\
\text { diter } \\
\text { ima }\end{array}$ \\
\hline
\end{tabular}

Sumber: hasil uji SPSS (data telah diolah).

Pada tabel diatas dapat diketahui bahwa variabel ini memiliki nilai signifikansi dari Levene's test sebesar 0,013 yang lebih kecil dari 0,05 , sehingga hasil uji yang digunakan adalah equal variances not assumed. Berdasarkan uji beda Independent sample t-test yang dilakukan pada variabel BOPO untuk BPRS yang mengikuti linkage program dan BPRS yang tidak mengikuti linkage program, diketahui bahwa nilai signifikansi dari variabel ini pada bagian equal variances not assumed adalah sebesar 0,060.

Nilai signifikansi dari rasio ini lebih besar dari 0,05 sehingga menunjukkan bahwa tidak terdapat perbedaan kinerja kevangan antara BPRS yang mengikuti linkage program dan BPRS yang tidak mengikuti linkage program pada sisi BOPO. 
Pratama, et al/Jurnal Ekonomi Syariah Teori dan Terapan Vol. 4 No. 6 Juni 2017: 493-504; ANALISIS KOMPARATIF KINERJA KEUANGAN BPRS LINKAGE PROGRAM DAN NON LINKAGE PROGRAM PERIODE 2014-2015

Uji Beda FDR

Tabel 6.

Uji Beda FDR Independent sample t-test

\begin{tabular}{|c|c|c|c|c|c|}
\hline \multirow[t]{2}{*}{ Var } & & \multicolumn{2}{|c|}{$\begin{array}{c}\text { Levene's } \\
\text { Test }\end{array}$} & \multirow[t]{2}{*}{ Sig. } & \multirow[t]{2}{*}{ Ket } \\
\hline & & $\mathbf{F}$ & Sig. & & \\
\hline \multirow{2}{*}{$\begin{array}{l}\text { FD } \\
R\end{array}$} & $\begin{array}{l}\text { Equal } \\
\text { varian } \\
\text { ce } \\
\text { assum } \\
\text { ed }\end{array}$ & \multirow{2}{*}{$\begin{array}{l}0,3 \\
86\end{array}$} & \multirow{2}{*}{$\begin{array}{c}0,5 \\
44\end{array}$} & $\begin{array}{l}0,0 \\
02\end{array}$ & $\begin{array}{c}\mathrm{H}_{0} \\
\text { ditolak } \\
\text { (terdap } \\
\text { at } \\
\text { perbed } \\
\text { aan) }\end{array}$ \\
\hline & $\begin{array}{l}\text { Equal } \\
\text { varian } \\
\text { ce } \\
\text { not } \\
\text { assum } \\
\text { ed }\end{array}$ & & & $\begin{array}{l}0,0 \\
02\end{array}$ & \\
\hline
\end{tabular}

Sumber: hasil uji SPSS (data telah diolah).

Pada tabel diatas dapat diketahui bahwa variabel ini memiliki nilai signifikansi dari Levene's test sebesar 0,544 yang lebih besar dari 0,05 , sehingga hasil uji yang digunakan adalah equal variances assumed. Berdasarkan uji beda Independent sample t-test yang dilakukan pada variabel FDR untuk BPRS yang mengikuti linkage program dan BPRS yang tidak mengikuti linkage program, diketahui bahwa nilai signifikansi dari variabel ini pada bagian equal variances assumed adalah sebesar 0,002.

Nilai signifikansi dari rasio ini lebih kecil dari 0,05 sehingga menunjukkan bahwa terdapat perbedaan kinerja kevangan antara BPRS yang mengikuti linkage program dan BPRS yang tidak mengikuti linkage program pada sisi FDR.

\section{Pembahasan}

Berdasarkan hasil uji beda menggunakan t test dan Mann-Whitney test yang telah dilakukan sebelumnya, maka hasil yang didapatkan untuk semua variabel yaitu Capital Adequancy Ratio (CAR), Non Performing Financing (NPF), Return On Asset (ROA), Beban Operasional Pendapatan Operasional (BOPO) dan Financing to Deposit Ratio (FDR) adalah sebagai berikut:

Tabel 7.

Hasil Uji Beda Semua Variabel pada BPRS Yang Mengikuti dan Tidak Mengikuti Linkage Program

\begin{tabular}{|c|c|c|}
\hline Var & Hasil Uji Beda & Ket \\
\hline CAR & Ho ditolak & $\begin{array}{c}\text { Terdapat } \\
\text { perbedaan }\end{array}$ \\
\hline NPF & Ho diterima & $\begin{array}{c}\text { Tidak } \\
\text { terdapat } \\
\text { perbedaan }\end{array}$ \\
\hline ROA & Ho diterima $^{\text {Tidak }} \begin{array}{c}\text { terdapat } \\
\text { perbedaan }\end{array}$ \\
\hline FDR & Ho ditolak & $\begin{array}{c}\text { Terdapat } \\
\text { perbedaan } \\
\text { Terdapat } \\
\text { perbedaan }\end{array}$ \\
\hline
\end{tabular}

Sumber: Hasil Uji Beda t test dan MannWhitney test

\section{Capital Adequacy Ratio (CAR)}

Berdasarkan uji yang telah dilakukan, dapat dinyatakan bahwa dari kedua kategori BPRS yaitu BPRS yang mengikuti linkage program dan BPRS yang tidak mengikuti linkage program pada periode 30 Maret 2014-30 Desember 2015 tersebut terdapat perbedaan kinerja keuangan dari segi rasio CAR. Hasil penelitian menunjukkan terdapat perbedaan kinerja keuangan dari segi rasio CAR pada BPRS yang mengikuti linkage program dan BPRS yang tidak mengikuti linkage program.

\section{Non Performing Financing (NPF)}


Berdasarkan uji yang telah dilakukan, dapat dinyatakann bahwa dari kedua kategori bank pembiayaan rakyat syariah yaitu BPRS yang mengikuti linkage program dan BPRS yang tidak mengikuti linkage program pada periode 30 Maret 2014 hingga 30 Desember 2015 tersebut terdapat perbedaan kinerja keuangan dari segi rasio NPF. Hasil penelitian menunjukkan terdapat perbedaan kinerja keuangan dari segi rasio NPF pada BPRS yang mengikuti linkage program dan BPRS yang tidak mengikuti linkage program.

\section{Return On Assets (ROA)}

Berdasarkan uji yang telah dilakukan, dapat dinyatakann bahwa dari kedua kategori bank pembiayaan rakyat syariah yaitu BPRS yang mengikuti linkage program dan BPRS yang tidak mengikuti linkage program pada periode 30 Maret 2014 hingga 30 Desember 2015 tersebut tidak terdapat perbedaan kinerja keuangan dari segi rasio ROA

\section{Beban Operasional Pendapatan Operasional (BOPO)}

Berdasarkan uji yang telah dilakukan, dapat dinyatakann bahwa dari kedua kategori bank pembiayaan rakyat syariah yaitu BPRS yang mengikuti linkage program dan BPRS yang tidak mengikuti linkage program pada periode 30 Maret 2014 hingga 30 Desember 2015 tersebut tidak terdapat perbedaan kinerja keuangan dari segi rasio BOPO.

\section{Financing to Deposit Ratio (FDR)}

Berdasarkan uji yang telah dilakukan, dapat dinyatakann bahwa dari kedua kategori bank pembiayaan rakyat syariah yaitu BPRS yang mengikuti linkage program dan BPRS yang tidak mengikuti linkage program pada periode 30 Maret 2014 hingga 30 Desember 2015 tersebut terdapat perbedaan kinerja keuangan dari segi rasio FDR.

\section{v. SIMPULAN}

Berdasarkan hasil penelitian dan juga pembahasan pada bab sebelumnya, maka simpulan yang dapat diambil adalah:

1. Berdasarkan uji beda $(a=0,05)$ pada periode 2014-2015 yang dilakukan dinyatakan bahwa pada faktor permodalan dengan rasio Capital Adequancy Ratio (CAR) terdapat perbedaan kinerja kevangan antara BPRS yang mengikuti linkage program dan BPRS yang tidak mengikuti linkage program.

2. Berdasarkan uji beda $(a=0,05)$ pada periode 2014-2015 yang dilakukan dinyatakan bahwa pada faktor kualitas aset dengan rasio Non Performing Ratio (NPF) terdapat perbedaan kinerja keuangan antara BPRS yang mengikuti linkage program dan BPRS yang tidak mengikuti linkage program.

3. Berdasarkan uji beda $(a=0,05)$ pada periode 2014-2015 yang dilakukan dinyatakan bahwa pada faktor rentabilitas dengan rasio Return On Asset (ROA) tidak terdapat perbedaan kinerja kevangan antara BPRS yang mengikuti linkage program dan BPRS yang tidak mengikuti linkage program. 
4. Berdasarkan uji beda $(a=0,05)$ pada periode 2014-2015 yang dilakukan dinyatakan bahwa pada faktor rentabilitas dengan rasio Beban Operasional Pendapatan Operasional (BOPO) tidak terdapat perbedaan kinerja kevangan antara BPRS yang mengikuti linkage program dan BPRS yang tidak mengikuti linkage program.

5. Berdasarkan uji beda $(a=0,05)$ pada periode 2013-2015 yang dilakukan dinyatakan bahwa pada faktor likuiditas dengan rasio Financing to Deposit Ratio (FDR) terdapat perbedaan kinerja keuangan antara BPRS yang mengikuti linkage program dan BPRS yang tidak mengikuti linkage program.

\section{DAFTAR PUSTAKA}

Kasmir. 2013. Analisis Laporan Keuangan. Jakarta: PT Raja Grafindo Persada.

Ismail. 2011. Perbankan Syariah. Jakarta: Kencana Prenada Media Group.

Muhammad, Teori dan Praktek Ekonomi Islam, (Yogyakarta: Dana Bhakti Prima Yasa, 1997) hal. 118

Republik Indonesia. 2012. Outlook Perbankan Syariah. Jakarta: Republik Indonesia.

Republik Indonesia. 2008. Undang-Undang Nomor 21 Tahun 2008 Tentang Perbankan Syariah. Jakarta: Republik Indonesia

Republik Indonesia. 2009. Peraturan Nomor : 03/Per/M.KUKM/III/2009 Menteri Negara Koperasi Dan Usaha Kecil Menengah Nomor 03/PER/M.KUKM/III/2009 Tentang Linkage Program. Jakarta: Republik Indonesia

Santoso, Singgih. 2014. Panduan Lengkap SPSS Versi 20 Edisi Revisi. Jakarta: Alex Media Komputindo.
Septian. 2013. Dasar-dasar Manajemen Bank Syariah. Jakarta: Raja Grafindo Persada

Sumitro, Warkum. 2002. Asas-asas Perbankan Islam dan LembagaLembaga Terkait BMI \& Takaful di Indonesia. Jakarta: PT Raja Grafindo Persada. 